\title{
Planning an integral drainage system for a coastal area
}

\author{
A. Trapote ${ }^{1} \&$ D. Pulido ${ }^{2}$ \\ ${ }^{1}$ Water and Environmental Science Institute, \\ University of Alicante, Spain \\ ${ }^{2}$ Technical University of Madrid, Spain
}

\begin{abstract}
Nowadays the management of water resources has become a top priority issue for Spanish public administration. This management of water resources is especially delicate in South eastern Spain where water is particularly scarce, principally as a result of the irregular distribution of rainfall and secondly, just as important, as a result of its overwhelming use in overly dense population areas where water has to meet great demands in many activities that range from agricultural, industrial, urban to sports facilities such as for golf courses among others. To counteract the effects derived from water scarcity, changes are being proposed to improve the management of the limited resources within a sustainable framework. In this way, an appealing alternative both from a technical and from an economic and environmental perspective would suggest the need to re-use urban wastewater to satisfy the demands that require nondrinkable water. Needless to say, in order to re-use urban wastewater, we need to depend on existing infrastructures for drainage and water treatment. Such infrastructures and those for regeneration and re-usage of urban wastewater feature the physical layout of an integral drainage system. In this paper we present the planning of an integral drainage system for a coastal area in Southeastern Spain. The proposal was developed as a result of an agreement reached between the Benissa city council in Alicante and the Institute of Water and Environmental Sciences of the University of Alicante.
\end{abstract}

Keywords: water resources management, sustainable development, integral drainage system, wastewater reuse. 


\section{Introduction}

South-eastern Spain has undergone a significant urban development in the last decade thanks to its pleasant weather conditions and to the outstanding services oriented mainly to tourism and residential development within others. Such growth has brought together many water consuming demands, intensifying the endemic water deficit which seriously threatens its economic evolution. Public administrations should be awoken to the fact by means of proposing suitable initiatives to ensure a sustainable development so as to keep up a reasonable level of economic growth in tune with the environmental resources.

Water demands have historically been met using proper conventional resources stored in aquifers and reservoirs and/or resources transferred from surplus river basins. Recently, non conventional resources such as sea water desalination are being employed. However, and for many different reasons, both water transfer and desalination plants are being rejected by some social sectors. In this scenario, the reuse of urban wastewater renders an accepted and a feasible alternative to manage a local water resource not only from a technical perspective but also from an economic and environmental point of view.

Valencian Community's regional administration is encouraging different initiatives to promote and boost urban wastewater re-use for non drinkable water demands in activities encompassing urban, agricultural, industrial and even sport facilities - golf courses, swimming pools and so on- aquifer artificial recharges and so forth. Such an initiative will gradually restore the balance, increasing water availability, saving drinkable water resources for urban supply as a result. Wastewater re-use has already been applied to agriculture and to golf courses to a certain extent but it has hardly had any effect in urban areas - for watering green areas, for fire nets, for recreational activities or for any such like activities - at least within an integral planning.

In this paper, the planning process of the integral drainage system for Benissa (Alicante) [1] will be described. Benissa constitutes a typical example of a coastal area featuring a severe water resource deficit which may show serious deficiencies in drainage and water treatment infrastructures whilst showing a dramatic urban development which yields great water demands that have to be met in a sustainable way.

\section{Wastewater re-use in a coastal area}

The implementation of a wastewater re-use project is made up of two essential and complementary processes [2]: 1 Defining the standard quality of any potential use of the water; and 2 Establishing the appropriate treatment processes and the recommended water quality standard levels for each of the identified potential uses.

The management of regenerated water usually requires the following technical steps to be accomplished. First, water is transported from the regeneration plant to the specific required location; second, water must be stored and its flow controlled to suit demand supplies; and finally, its use must be 
subjected to pre-defined policies. These three steps constitute the core of any planned wastewater re-use project.

Indeed, wastewater re-use (or simply put, water re-use) does yield an increase of available water resources in an area [3]. Figure 1 below shows two different approaches to water use in coastal areas. Figure 1(a) depicts the system containing the resources (Rt) feeding the system that supplies the total demand $(\mathrm{Db})$ from which a net demand is satisfied (Dn) and the rest $(\mathrm{R})$, which we call return. If $\mathrm{R}$, once treated, is directly released into the sea, the available resources to meet new demands placed downstream would be $\mathrm{Rd}$. This system, as can be seen, lacks the re-use capabilities. Figure 1(b) shows the same system to which water re-use capabilities have been added. In this case, the system is capable of re-using $\mathrm{R}$ which added to $\mathrm{Rd}(\mathrm{R}+\mathrm{Rd})$ renders an increase in water resources as a result.

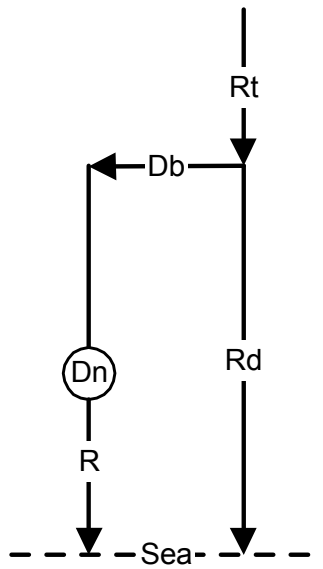

(a)

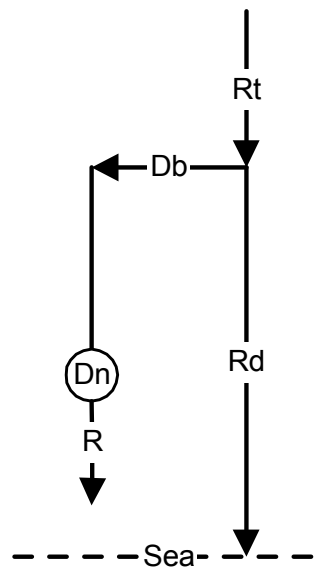

(b)

Figure 1: Schematic of water use in coastal areas: (b) with reuse and (a) without reuse.

\section{Location and characteristics of the case study}

Metropolitan Benissa is located on the coast of south-eastern Spain (Fig.2), 71 $\mathrm{km}$ north of Alicante city. It stretches out for about $69 \mathrm{~km}^{2}$. Our case study centres in an area $3 \mathrm{~km}$ southeast of Benissa city centre, encompassing a coastal fringe of length $4 \mathrm{~km}$ and of width $2 \mathrm{~km}$ with a total area of approximately 8 $\mathrm{km}^{2}$.

This spot is particularly rugged, featuring very steep slopes running northeastsoutheast into the sea. Their heights vary from $+250 \mathrm{~m}$ to $+0 \mathrm{~m}$ in less than 3,000 metres, presenting gradients of over $8 \%$.

Benissa's average maximum and minimum temperatures are $22{ }^{\circ} \mathrm{C}$ and $13{ }^{\circ} \mathrm{C}$ respectively, being $17.5{ }^{0} \mathrm{C}$ its mean annual temperature. Its rainfall pattern 
presents alternating cycles of dry and wet years, typical of the Mediterranean climate. Its mean annual rainfall reaches $680 \mathrm{~mm}$, with an average of 70 rainy days per year, ranging from minimum of $350 \mathrm{~mm}$ to maximum values of $950 \mathrm{~mm}$.

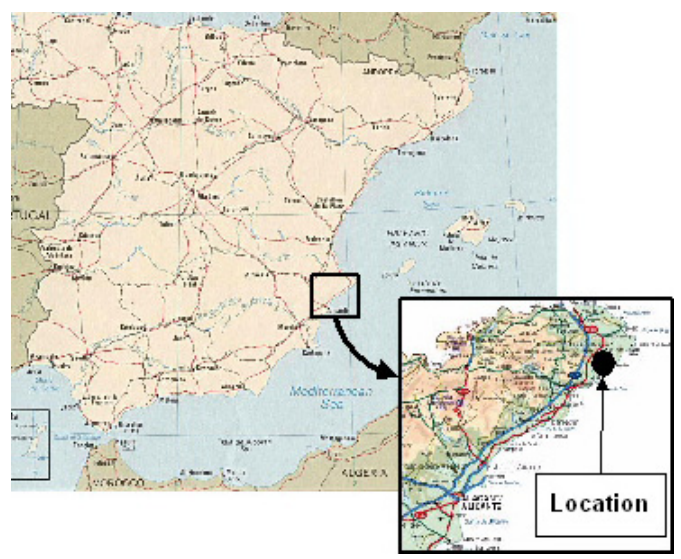

Figure 2: Location map.

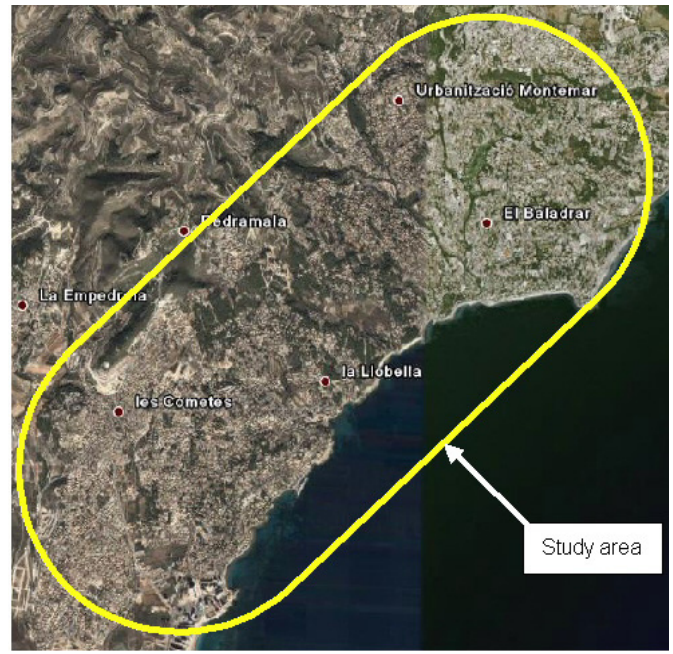

Figure 3: $\quad$ Air picture of the study area.

The area under study comprises urban and prospective urban zones contemplated in the Urban City Planning. These zones will mainly consist of residential areas and tertiary services associated with tourism, such as hotels, food stores and the like together with private and public facilities.

It is necessary to point out at this stage that many of the existing residential developments may lack sewerage. Should they have it, it inevitably is in need of repair, the reasons being its oldness and/or its having been left unattended for 
years. As for water treatment, the zone boasts of elementary individual initiatives and/or local wastewater treatment plants scattered around, yielding adverse results. Some of the pseudo-treated water permeates through the soil into the underground rivers, polluting it and the rest gets wasted into the sea either by runoffs, or by canals, polluting the sea.

Figure 4 presents the current state of urban drainage so far described.

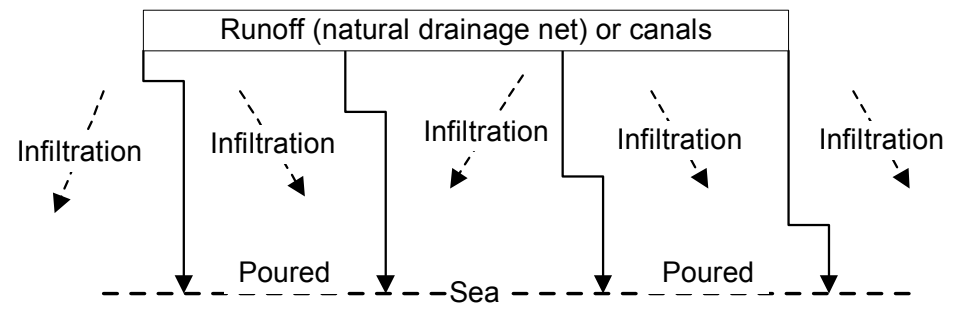

Figure 4: $\quad$ Schematic of the existing drainage in the urban area.

\section{Data and hypothesis for our case study}

The urban data, the data forecast by Benissa's Urban City Planning [UCP] and the data resulting from drinkable water consumption figures supplied by the Metropolitan Water Department have been considered to estimate water demands for the area.

The area under study comprises 42 residential areas, of which 20 are potential. The current number of houses amounts to 4,619 in the metropolitan area and the UCP foresees 1,782 more houses for the area, reaching a total figure of 6,401 houses in a year's time. Provided that there are 2.54 inhabitants per dwelling, the total population is estimated to be 16,260 people.

According to the data provided, water consumption reaches an average of 200 $\mathrm{ml} /$ person-day. However, Benissa's UCP has fixed it to be $250 \mathrm{ml} /$ person-day, and this is the value we have taken for the reason that it poses more restrictive conditions to the water balance. Therefore, we have estimated that the drinkable water need for urban supply will be $1,500,000 \mathrm{~m}^{3}$ per year approximately. However, there are two other factors which will pay key roles in water consumption: a golf course of eight holes and the green areas. The golf course will presumably need $550,000 \mathrm{~m}^{3}$ per year and the green areas another 280,000 $\mathrm{m}^{3}$ per year, adding $830,000 \mathrm{~m}^{3}$ per year to the previous water consumption estimation, yielding a total water demand of 2,330,000 $\mathrm{m}^{3}$ per year as a result for the area.

\section{Objectives}

Our main objective is to improve the water resources management in the area by regenerating and re-using treated urban wastewater so that, at least, the demands requiring non drinkable water can be met within the Water Framework Policy 
[4], especially with regards to land water protection - superficial and groundwater - coastal areas and sustainable development.

As a specific objective we pursue to satisfy most of the water demand through developing water resources assigned as urban supply demand only, balancing an area which initially is characterized by water shortage.

In order to be successful in such an enterprise, we need to implement an integral drainage system. This implementation will constitute a means for collecting, transporting and treating sewage water, as well as for regenerating and re-using it. In short, the goal is to move a step further from the situation depicted in figure 4 and from there move to the next step - figure 5 - and finally reach the one presented in figure 6 .

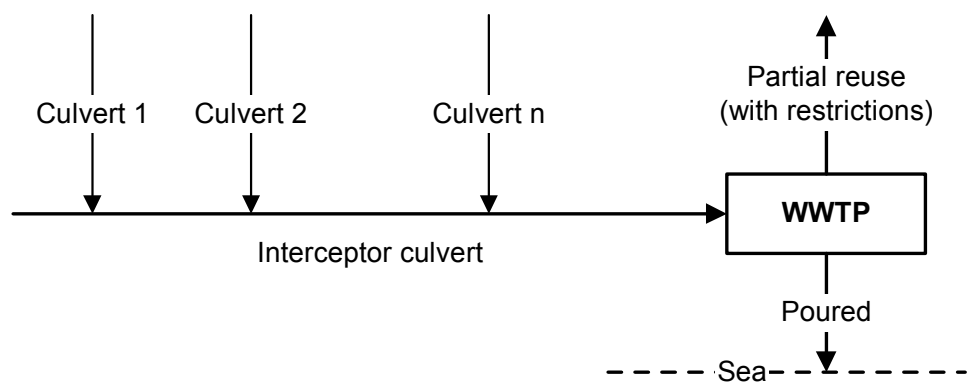

Figure 5: $\quad$ First phase of the integral drainage system.

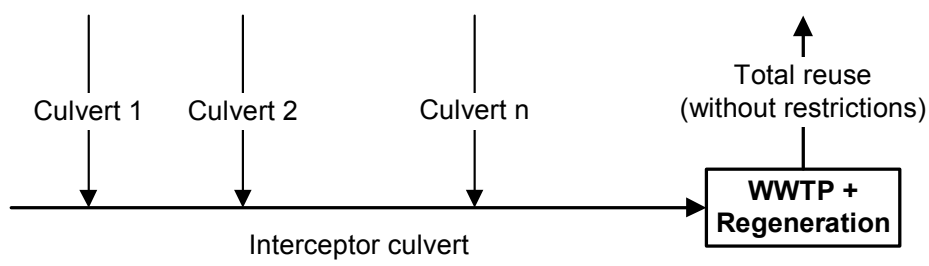

Figure 6: Second phase of the integral drainage system.

\section{Elements of an integral drainage system}

An integral drainage system (IDS) can be defined as the facilities required for collecting, transporting and treating wastewater so that it can be fed into the system in the best of conditions and in accordance with the environmental regulations pertaining water resources.

The system consists of inputs - system feeders - outputs and in between processes that are realized by different interrelated elements. In an IDS, the 
inputs consist of polluted urban wastewater (UW); the outputs of treated water (TW), polluted water subjected to a particular treatment - usually biological and the processes of the step-by-step phases wastewater experience in their passage through the different system elements.

The system elements, whose function is to perform the in between processes already mentioned, are the sewer net and the water treatment plant (WWTP). The former, bearing as essential components the emitter and interceptor as essential, components collects and transports the UW to the WWTP. The latter treats the UW before submitting to the receiving facilities for possible re-use - with certain limitations.

Figure 7 shows the concepts analysed as well as a UW flowchart from its input into the IDS to its output as TW.

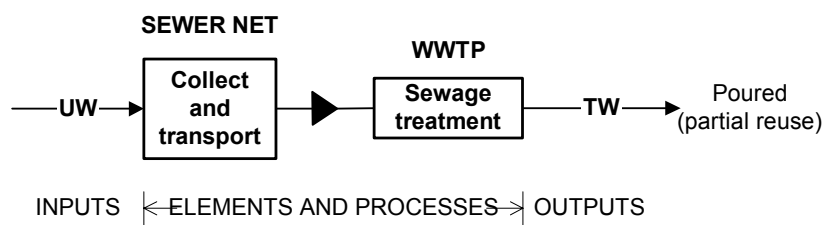

Figure 7: General schematic and IDS flowchart.

From a comprehensive perspective, such definition of an IDS includes the UW regeneration and re-use facilities so that the regenerated water (RW) it can be reintroduced into the system. In other words, UW undergoes a treatment process so that it achieves a certain quality standard levels to be re-used where required, and what is most important, without any limitations.

However, the project calls for a significant economic investment and, consequently, for a careful planning. Priorities and the different stages to be met need to be established. In so doing, investments can be phased and work strategies arranged according to the available economic resources.

As a consequence, and generally speaking, an IDS could be designed in two stages. The first for short and medium term planning oriented to solving the basic water infrastructures to meet current residential development demands; and the second for long term planning oriented to designing an integral water management to meet old and new residential area demands.

Table 1: $\quad$ Phases, elements (infrastructures) and processes included in the IDS.

\begin{tabular}{|c|l|l|}
\hline Phases & \multicolumn{1}{|c|}{ Elements } & \multicolumn{1}{c|}{ Processes } \\
\hline \multirow{2}{*}{1} & Sewer net & Collect and transport UW \\
\cline { 2 - 3 } & WWTP (Secondary treatment) & Treatment $\rightarrow \mathrm{TW}$ \\
\hline \multirow{3}{*}{2} & WWTP (Tertiary treatment) & Regeneration $\rightarrow \mathrm{RW}$ \\
\cline { 2 - 3 } & Tank & RW storage \\
\cline { 2 - 3 } & Distribution net & Reuse \\
\hline
\end{tabular}


Table 1 below shows the two phases, the different elements and the processes involved in an IDS.

An extended general IDS is presented in Figure 8 schematically. The inputs, outputs, elements and the corresponding processes are highlighted:

- Inputs.

- Phase 1: UW.

- $\quad$ Phase 2: TW (from the secondary treatment).

- Outputs.

- $\quad$ Phase 1: TW that could be reused in some demands (with restrictions), and TW from the secondary treatment (to the tertiary treatment).

- $\quad$ Phase 2: RW (to reuse).

- $\quad$ Elements.

- $\quad$ Phase 1: Sewer net and WWTP (secondary treatment).

- $\quad$ Phase 2: WWTP (tertiary treatment), tank and distribution net.

- Processes.

- $\quad$ Phase 1: collect, transport and wastewater treatment (secondary treatment).

- $\quad$ Phase 2: regeneration (tertiary treatment), storage and distribution of RW.

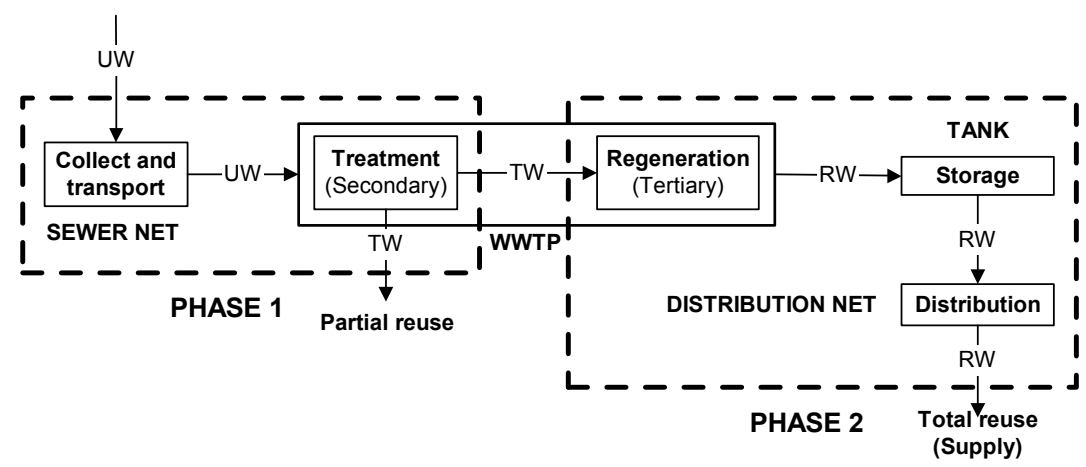

Figure 8: "Extended" general schematic and IDS flowchart.

\section{Expected results}

Through an IDS we expect to achieve the proposed objectives pertaining the better management of water resources in an area characterised by scarce water availability to satisfy most of its demand by solely resorting to resources assigned to urban supply.

Taking into account Figure 1(b), assuming losses of $20 \%(\mathrm{Dn}=0.80 \times \mathrm{Db})$ and considering that approximately $75 \%$ of the flows dedicated to urban supply demands can be re-used [5] $-\mathrm{R}=0.75 \times \mathrm{Dn}=0.75 \times 0.80 \times \mathrm{Db}=0.60 \times \mathrm{Db}$ then, the available water resources downstream Dn to supply new demands would be $\mathrm{R}+\mathrm{Rd}=(0.60 \times \mathrm{Db})+\mathrm{Rd}$, which means that the available water resources in the area are increased by $60 \%$. 
If we apply this data to our case study, we get that $\mathrm{Db}=1,500,000 \mathrm{~m}^{3} /$ year; $\mathrm{Dn}=0.80 \times 1,500,000=1,200,000 \mathrm{~m}^{3}$ /year; $\mathrm{R}=0.75 \times 1,200,000=900,000$ $\mathrm{m}^{3} /$ year. It comes as a result that the available water resources downstream Dn to meet new demands would be $900,000 \mathrm{~m}^{3} /$ year $+\mathrm{Rd}$. There would be enough water to upkeep the golf course and the green areas, whose demands have been calculated to be $830,000 \mathrm{~m}^{3} /$ year. It follows that these demands could be perfectly met by the water re-use planning we develop if correctly implemented.

Recalling the estimated water needs for the area discussed previously, we stated that $2,330,000 \mathrm{~m}^{3} /$ year was the amount of water to be satisfied to meet the area's demand to guarantee urban and green areas supplies. However, we have proved that the originally proposed $1,500,000 \mathrm{~m}^{3} /$ year for urban supply will cater for not only urban but sport facilities water supply. If need be, the excess of water supply could be employed to meet other urban demands.

\section{Conclusions}

The following conclusions could be made from the analysis performed:

1. An IDS in a coastal area constitutes a valuable means to optimize the available water resources through an appropriate integral management to enable balance between supply resources and demands in areas which feature scarce water resources.

2. The main goal of any IDS should be the re-use of all the wastewater that feeds the return channel from the urban supply. It will be used to satisfy demands that require non drinkable water, thus bringing about more drinkable water for extra urban demands.

3. The IDS is capable of increasing available water resources in as much as $60 \%$ of the $\mathrm{Db}$ (total urban demand), percentage that can be made higher should the losses in the supply and drainage conduits be reduced.

4. An IDS planning should contain the following components:

- Water Balance

- Initial conditions

- Analysis of current and future situation

- Conditioning factors

- Objectives

- Use policy

- IDS design

- Technical, economical and environmental evaluation of alternatives

- Selection of the best alternative

- Work strategy (spatial and temporal definition)

- Technical and economical programming

\section{Acknowledgements}

We wish to acknowledge Professor Ana Amilburu for her invaluable translation of this document and for her insightful suggestions to make this paper mean what its authors had in mind. 
12 Water Pollution IX

\section{References}

[1] Trapote, A., Estudio de alternativas para el saneamiento integral de la zona litoral de Benissa, 2004.

[2] Mujeriego, R., Evolución y perspectiva de la reutilización de aguas en España, 1998.

[3] Balairón, L., Gestión de recursos hídricos, 2000.

[4] Directiva 2000/60/CE del Parlamento Europeo y del Consejo, Directiva Marco del Agua, 2000.

[5] Urrea, M.A., El Plan Hidrológico de la Demarcación Hidrográfica del Segura: un nuevo reto de Gestión Integrada de los Recursos Hídricos, 2007. 